\title{
Microsurgical Vascular Manipulation in Aneurysm Surgery and Delayed Ischemic Injury
}

\author{
Muhammad Omar Chohan, Andrew P. Carlson, Cristina Murray-Krezan, \\ Christopher L. Taylor, Howard Yonas
}

\begin{abstract}
Background: The role of aggressive surgical manipulation with clot evacuation, arachnoid dissection, and papaverine-guided adventitial dissection of large vessels during ruptured aneurysm surgery in reducing vasospasm is controversial. Here we describe a single-institution experience in aneurysm surgery outcomes with and without aggressive surgery. Methods: We performed retrospective analysis of all patients $>18$ years of age with subarachnoid hemorrhage (SAH) from anterior circulation aneurysms between 2008 and 2013 at the University of New Mexico Hospital. Vasospasm was characterized on days 3 through 14 after SAH based on: (1) angiography, (2) vasospasm requiring angiographic intervention, (3) development of delayed ischemic neurologic deficit (DIND), and (4) radiological appearance of new strokes. Results: Of 159 patients, $114(71.6 \%)$ had "aggressive" and 45 (28.3\%) had standard microsurgery. More than 60\% of patients presented with a Hunt and Hess score of $\geq 3$ and a Fisher grade (FG) of 4 . Compared with standard surgery, there was a statistically significant decrease in the incidence of DIND in patients undergoing aggressive surgery $(18.4 \%$ vs $37.8 \%, p=0.01)$. Moreover, there was a reduction in the number of new strokes by $30 \%$ in the aggressive surgery group with moderate or higher degrees of vasospasm $(46.0 \%$ vs $76.5 \%$, $\mathrm{p}=0.06)$. In the same group with FG 4 $\mathrm{SAH}$, however, this difference was more than $50 \%(30 \%$ vs $64.7 \%, \mathrm{p}=0.02)$. Conclusions: We conclude that aggressive surgical manipulation during aneurysm surgery results in lower incidence of DIND and new strokes. This effect is most pronounced in patients with FG 4 SAH.
\end{abstract}

RÉSUMÉ: Gestes microchirurgicaux vasculaires dans la chirurgie des anévrismes et dans le cas de lésions ischémiques retardées. Contexte: Lors d'interventions chirurgicales consécutives à des ruptures d'anévrismes, l'impact des gestes microchirurgicaux agressifs (évacuation de caillots ; dissection de l'arachnoïde ; sous l'effet de la papavérine, dissection sous-adventitielle d'importants vaisseaux sanguins) visant à réduire les vasospasmes demeure controversé. Nous voulons décrire ici une expérien1ce menée au sein d'un seul établissement hospitalier en ce qui concerne l'impact sur les anévrismes d'une chirurgie courante et d'une chirurgie plus agressive. Méthodes: Nous avons mené une analyse rétrospective des dossiers de tous les patients âgés de plus de 18 ans de l'Hôpital de l'Université du Nouveau-Mexique ayant été victimes, de 2008 à 2013, d'une hémorragie sous-arachnoïdienne (HSA) à la suite d'anévrismes de la circulation sanguine. À la suite d'une HSA, du jour 3 au jour 14, des vasospasmes ont été décrits en se fondant sur : (1) une angiographie ; (2) des vasospasmes nécessitant une intervention angiographique ; (3) l'apparition d'une ischémie cérébrale retardée (ICR); et (4) les indices radiologiques de nouveaux AVC. Résultats: Sur 159 patients, 114 (71,6\%) ont bénéficié d'une microchirurgie dite agressive et 45 autres (28,3\%) d'une microchirurgie courante. Plus de $60 \%$ des patients ont obtenu un score de $\geq 3$ sur l'échelle de Hunt et Hess et 4 sur l'échelle de Fisher. En comparaison avec une intervention chirurgicale courante, il y a eu une diminution statistiquement significative de la fréquence d'ICR chez les patients qui avaient subi une intervention chirurgicale agressive ( $18,4 \%$ contre $37,8 \%$; $\mathrm{p}=0,01$ ). De plus, on a pu noter, outre une diminution de $30 \%$ du nombre de nouveaux AVC, des degrés modérés ou plus élevés de vasospasmes au sein du groupe de patients ayant subi une chirurgie agressive $(46,0 \%$ contre $76,5 \% ; p=0,06)$. Dans le même groupe où les individus avaient été victimes d'une HSA et obtenu 4 à l'échelle de Fisher, cette différence était toutefois de plus de 50\% (30\% contre 64,7\%; p=0,02). Conclusions: Nous concluons que des gestes microchirurgicaux agressifs lors d'une chirurgie des anévrismes ont pour conséquence une fréquence plus faible d'ICR et de nouveaux AVC. Cette conséquence est particulièrement marquée dans les cas d'HSA dont le score se situe à 4 sur l'échelle de Fisher.

Keywords: Aneurysm, Clipping, Delayed ischemic neurologic deficit (DIND), Infarct, Subarachnoid hemorrhage doi:10.1017/cjn.2016.408

Can J Neurol Sci. 2017; 44: 410-414

Subarachnoid hemorrhage (SAH) following ruptured intracranial aneurysm is often complicated by shunt-dependent hydrocephalus (SDHCP), clinically significant vasospasm, and delayed ischemic events. Intraoperative maneuvers to lower these complications, such as aggressive clot evacuation, ${ }^{1,2}$ blood vessel manipulation, and communication of ventricles to the cisternal space, ${ }^{3-6}$ have been advocated as an adjunct to aneurysm surgery. Microsurgical fenestration of lamina terminalis (FLT) and/or Liliequist membrane (LM) during aneurysm clipping, first described by Dandy and popularized by Yasargil to achieve brain relaxation, ${ }^{7,8}$ has been

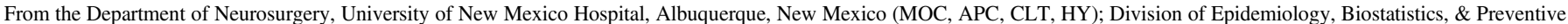
Medicine, Department of Internal Medicine, University of New Mexico Health Sciences Center, Albuquerque, New Mexico (CM-K).

Received January 5, 2016. Final Revisions Submitted July 26, 2016. Date of Acceptance July 27, 2016.

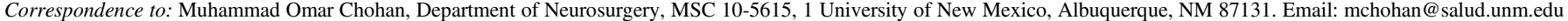


described to reduce the incidence of clinically relevant vasospasm and SDHCP. By providing a continuous cisternal lavage, ventriculocisternostomy is thought to improve cerebrospinal fluid (CSF) dynamics and prevent subarachnoid blood from causing arachnoid fibrosis and vascular inflammation., ${ }^{4,-11}$

We sought to study the role these intraoperative maneuvers during aneurysm surgery. Here, we show that the incidence of clinically relevant vasospasm is significantly lower when these intraoperative maneuvers are used during microsurgical clipping. This difference is more pronounced with higher Fisher grade (FG) SAH.

\section{Methods}

\section{Selection Criteria}

Patients were identified retrospectively under an approved institutional review board protocol. The study population included patients aged 18 years or older (1) with acute SAH resulting from a ruptured anterior circulation aneurysm who presented at our service between January 2008 to December 2013; (2) who underwent pterional craniotomy, which allows surgical access to the lamina terminalis and LM during aneurysm clipping; and (3) in whom presence of intracranial aneurysms were confirmed radiographically by computed tomography (CT) angiogram (CTA) or conventional four-vessel diagnostic cerebral angiogram (DSA). All surgeries were performed by two surgeons (A and B), with (group A) or without (group B) meticulous clot evacuation, establishing CSF dynamics by creating alternate routes (i.e. FLT and FLM [Fenestration of Lamina Terminalis]) and adventitial dissection of major vessels using papaverine. All postoperative care was provided in the Neuroscience Intensive Care Unit using uniform institutional protocols for management of aneurysmal SAH, thus minimizing patient-patient variation in postoperative care.

\section{Key Definitions}

The presence of SAH was confirmed either by CT imaging or by lumbar puncture demonstrating xanthochromia and increased red cells in the CSF of patients with clinical suspicion of a ruptured intracranial aneurysm. Vasospasm was characterized on days 3 through 14 post-SAH based on (1) angiographic evidence of vascular narrowing in the moderate, moderate to severe, and severe category as read by neuroradiologists; (2) whether vasospasm required intervention (such as verapamil infusion or balloon angioplasty) during angiography; (3) development of a delayed ischemic neurological deficit (DIND) (i.e. a delayed neurological deficit [3-14 days after $\mathrm{SAH}]$ ) that is not explained by other causes (such as hydrocephalus, medications, seizures, etc); and (4) presence of new hypodense areas on postsurgery CT imaging during the susceptibility period (i.e. postsurgery days 3-14). All patients had a head CT scan on postoperative day (POD) 1 to evaluate immediate postsurgical strokes (e.g. perforator infarcts) and edema. Thus, only new areas of hypodensity on PODs 3 through 14 were considered new strokes. Mortality and morbidity outcome in the two groups was determined by Glasgow Outcome Scale (GOS) and modified Rankin scale (mRS).

\section{Statistical Analysis}

Student's two-sample $t$ test and Wilcoxon rank-sum test were used for univariate comparisons between group means and medians. Chi-square and Fisher exact tests were used for univariate comparisons between categorical variables.
Multivariable logistic regression was performed for each of the following independent, dichotomous outcomes: angiographic vasospasm, DIND, and occurrence of new stroke. Stepwise and backward variable selection methods were used to select independent predictors for each of these outcomes. The following predictors were included in the initial regressions: age, sex, Hunt and Hess $(\mathrm{HH})$ score ( $\leq 3$ vs $>3$ ), FG ( $\leq 3$ vs 4 ), initial Glasgow Coma Scale (GCS; $\leq 9$ vs $>9$ ), as well as all second-order interactions. Adjusted odds ratios and their 95\% confidence intervals were obtained for these outcomes. Statistical analysis was performed using SAS 9.3 (SAS Institute Inc., Cary, NC).

\section{RESULTS}

\section{Population Characteristics}

Of the 562 patients screened (including those with traumatic SAH), 159 satisfied the inclusion criteria (Table 1). Of those, $114(71.6 \%)$ were in group A and $45(28.3 \%)$ in Group g with a

Table 1: Clinical and radiographic characteristics

\begin{tabular}{|c|c|c|c|}
\hline & $\begin{array}{l}\text { Group A } \\
(\mathrm{n}=114)\end{array}$ & $\begin{array}{c}\text { Group B } \\
(n=45)\end{array}$ & $p$ value \\
\hline Age (mean, SD) & $56.7( \pm 12.4)$ & $52.2( \pm 11.7)$ & $0.04 *$ \\
\hline ICU LOS (median, Q1-Q3) & $12(9-16)$ & $11(9-16)$ & $0.55^{\dagger}$ \\
\hline LOS & $16(13-24)$ & $14(12-24)$ & $0.37^{\dagger}$ \\
\hline Follow-up & $78(30-274)$ & $98(41-222)$ & $0.99^{\dagger}$ \\
\hline Initial GCS & $14(8-15)$ & $14(9-15)$ & $0.73^{\dagger}$ \\
\hline HH score & $3(2-4)$ & $3(2-4)$ & $0.65^{\dagger}$ \\
\hline G & $4(3-4)$ & $4(3-4)$ & $0.54^{\dagger}$ \\
\hline Male:female & $36: 78(68.4)$ & $16: 29(64.4)$ & 0.63 \\
\hline \multicolumn{4}{|l|}{$\mathrm{HH}, \mathrm{n}(\%)$} \\
\hline I, II & $41(36)$ & $19(42.2)$ & \multirow[t]{2}{*}{$0.46^{\ddagger}$} \\
\hline III-V & $73(64.0)$ & $26(57.8)$ & \\
\hline \multicolumn{4}{|l|}{ FG, n (\%) } \\
\hline $1,2,3$ & $33(29.0)$ & $15(33.3)$ & \multirow[t]{2}{*}{$0.59^{\ddagger}$} \\
\hline 4 & $81(71.0)$ & 30 (66.7) & \\
\hline \multicolumn{4}{|l|}{ Site, n (\%) } \\
\hline AComm & $51(44.7)$ & $21(46.6)$ & \multirow[t]{4}{*}{$0.80^{\ddagger}$} \\
\hline ICA & $9(7.9)$ & $6(13.3)$ & \\
\hline MCA & $33(28.9)$ & $12(26.7)$ & \\
\hline PComm & $21(18.4)$ & $6(13.3)$ & \\
\hline \multicolumn{4}{|l|}{ Size, n (\%) } \\
\hline $0-3 \mathrm{~mm}$ & $18(16.1)$ & $9(20.0)$ & \multirow[t]{4}{*}{$0.50^{\ddagger}$} \\
\hline 3-7 mm & $54(48.2)$ & $25(55.6)$ & \\
\hline $7-13 \mathrm{~mm}$ & $31(27.7)$ & $6(13.3)$ & \\
\hline$>13$ & $9(8)$ & $5(11.1)$ & \\
\hline \multicolumn{4}{|c|}{$\begin{array}{l}\text { *p value obtained from two-sample } t \text { test for means. } \\
\text { p value obtained from the exact Wilcoxon two-sample test. } \\
\text { Values in bold indicate statistically significant differences. } \\
\text { Acomm = anterior communicating artery; FG = Fisher grade; } \\
\text { GSC = Glasgow coma score; } \mathrm{HH}=\text { Hunt and Hess; ICA = internal carotid } \\
\text { artery; } \mathrm{ICU}=\text { intensive care unit; LOS = length of stay; MCA = middle } \\
\text { cerebral artery; Pcomm = posterior communicating artery. }\end{array}$} \\
\hline
\end{tabular}


Table 2: Radiographic vasospasm

\begin{tabular}{|c|c|c|c|c|c|}
\hline & & & Group A $(n=114)$ & Group B $(n=45)$ & p value $^{a}$ \\
\hline \multicolumn{3}{|c|}{ Preoperative vasospasm, n (\%) } & $9(7.9)$ & $5(11.1)$ & 0.52 \\
\hline \multirow{4}{*}{$\begin{array}{l}\text { Angiographic } \\
\text { vasospasm }\end{array}$} & \multirow[t]{2}{*}{ All patients } & Any vessel & $36(31.6)$ & $21(46.7)$ & 0.07 \\
\hline & & Ipsilateral & $35(30.7)$ & $21(46.7)$ & 0.06 \\
\hline & \multirow[t]{2}{*}{ Fisher grade 4} & Any vessel & $30(37.0)$ & $17(56.7)$ & 0.06 \\
\hline & & Ipsilateral & $29(35.8)$ & $17(56.7)$ & 0.05 \\
\hline \multirow{2}{*}{\multicolumn{2}{|c|}{ Need for angiographic intervention }} & All & $15(13.2)$ & $9(20.0)$ & 0.28 \\
\hline & & Fischer grade 4 & $13(16.3)$ & $8(26.7)$ & 0.22 \\
\hline
\end{tabular}

${ }^{\mathrm{a}}$ Chi-square test for independence.

mean age (standard deviation) of 55.4 (12.3) years and follow-up of 184 days. Patients in group A were slightly older than those in group B: 56.7 (12.4) versus 52.2 (11.7) years, respectively $(\mathrm{p}=0.04)$. More than $60 \%$ of patients presented with an $\mathrm{HH}$ score of 3 or more and FG of 4 . Between the two groups, length of intensive care unit and total hospital stay were similar $(\mathrm{p}=0.55$ and 0.37 , respectively). More than $45 \%$ of aneurysms were in the anterior communicating artery region, $28 \%$ in the middle cerebral artery, and $17 \%$ in the posterior communicating artery, with similar distribution between the two groups. Almost two-thirds of all ruptured aneurysms were $<7 \mathrm{~mm}$ in size, whereas $20 \%$ were 7 to $13 \mathrm{~mm}$ and $<10 \%$ were $>13 \mathrm{~mm}$.

\section{Vasospasm}

Based on radiologist's interpretation of pretreatment angiogram (usually a CTA), the incidence of pretreatment vasospasm was similar between the two groups $(p=0.52)$. All patients had a DSA between days 3 and 10 (median, 7 days) after aneurysm treatment. Overall, 36\% of patients developed moderate or higher degrees of angiographic vasospasm (Table 2). There was a nonsignificant trend toward less radiographic vasospasm ipsilateral to the ruptured aneurysm (30.7\% in group A and $46.7 \%$ in group $B, p=0.06)$ and in all vessels ( $31.6 \%$ vs $47.7 \%, \mathrm{p}=0.07)$ between the two groups. This difference reached statistical significance in the cohort of patients that presented with SAH with intraventricular hemorrhage (i.e. FG 4; $35.8 \%$ in aggressive vs $56.7 \%$ in standard surgical groups, $p=0.05$, ipsilateral vasospasm) (Table 2).
There was a statistically significant difference between the occurrences of DIND within the two groups $(18.4 \%$ vs $37.8 \%$, $\mathrm{p}=0.01$ ). This effect was maintained in patients with FG $4 \mathrm{SAH}$ $(p=0.04)$. There was no difference in the need for angiographic interventions, such as balloon angioplasty or verapamil administration, to relieve vasospasm during surveillance DSA (Table 3).

The overall incidence of new strokes was $28.5 \%$. In patients with moderate or higher degree of vasospasm, there were $30 \%$ fewer strokes in group A than in group B $(46.4 \%$ vs $76.5 \%$, $\mathrm{p}=0.06$ ). In the same group of patients with FG 4 SAH, however, the difference was $>50 \%$ (30\% vs $64.7 \%, \mathrm{p}=0.02)$ (Table 3 ).

Using multivariable logistic regression, we identified independent predictors for the occurrence of angiographic vasospasm, DIND, and new strokes. We found that as age increased, the odds of angiographic vasospasm decreased by $3 \%$ per year (95\% confidence interval [CI]: $1 \%-5 \%$ ). Subjects with $\mathrm{HH}$ scores $\geq 3$ were 3.97 (95\% CI: 1.96-8.01) times more likely than subjects with scores $<3$ to experience any vasospasm. Significant factors associated with DIND were $\mathrm{HH}$ score, with scores $\geq 3$ increasing the odds of DIND by 2.82 (95\% CI: 1.24-6.39), and an interaction between age and the FG. In patients with FG $<4$, the odds of DIND decreased by $6 \%$ per year (95\% CI: $0.1-12)$. In subjects with FG 4 SAH, the odds of DIND did not change with increasing age. Significant factors associated with occurrence of new strokes on postintervention days 3 through $14 \mathrm{CT}$ scans were HH score and the interaction between GCS and sex. Patients with $\mathrm{HH}$ scores $\geq 3$ were 3.37 (95\% CI: 1.48-7.70) times more likely than subjects with $\mathrm{HH}$ scores $<3$ to experience a new stroke. Males with initial

Table 3: Clinical vasospasm

\begin{tabular}{|c|c|c|c|c|c|}
\hline & & & Group A $(n=114)$ & Group B $(n=45)$ & p value \\
\hline \multirow[t]{2}{*}{ DIND } & \multicolumn{2}{|l|}{ All patients } & $21(18.4)$ & $17(37.8)$ & $0.01^{*}$ \\
\hline & \multicolumn{2}{|l|}{ FG 4} & $19(23.8)$ & $13(43.3)$ & $0.04^{*}$ \\
\hline \multirow{3}{*}{$\begin{array}{l}\text { New strokes } \\
\text { (All patients) }\end{array}$} & \multicolumn{2}{|l|}{ All patients } & $28(24.8)$ & $17(37.8)$ & $0.10^{*}$ \\
\hline & \multirow[t]{2}{*}{ With angiographic vasospasm } & Any vessel & $13(46.4)$ & $13(76.5)$ & $0.06^{\dagger}$ \\
\hline & & Ipsilateral & $13(46.4)$ & $13(76.5)$ & $0.06^{\dagger}$ \\
\hline \multirow{3}{*}{$\begin{array}{l}\text { New strokes } \\
\text { (FG 4) }\end{array}$} & \multicolumn{2}{|l|}{ All patients } & $22(27.2)$ & $13(43.3)$ & $0.11^{*}$ \\
\hline & \multirow[t]{2}{*}{ With angiographic vasospasm } & Any vessel & $9(30.0)$ & $11(64.7)$ & $0.02^{*}$ \\
\hline & & Ipsilateral & $9(31.0)$ & $11(64.7)$ & $0.03^{*}$ \\
\hline
\end{tabular}

*p value obtained from the chi-square test for independence.

${ }^{\dagger} \mathrm{p}$ value obtained from Fisher's exact test.

$\mathrm{DIND}=$ delayed ischemic neurological deficit $\mathrm{FG}=$ Fisher grade. 


\section{Table 4: Clinical outcome}

\begin{tabular}{l|l|c|c|c}
\hline Clinical outcome & & Group A & Group B & p value \\
\hline \multirow{2}{*}{$\begin{array}{c}\text { Median } \\
\text { (Q1-Q3) }\end{array}$} & GOS at discharge & $4(3-5)$ & $4(3-5)$ & $0.36^{*}$ \\
\cline { 2 - 5 } & mRS at discharge & $3(1-4)$ & $3(1-4)$ & $0.68^{*}$ \\
\cline { 2 - 5 } & GOS at last followup & $5(4-5)$ & $5(3-5)$ & $0.23^{*}$ \\
\cline { 2 - 5 } & mRS at last followup & $1(0-3)$ & $2(0-4)$ & $0.51^{*}$ \\
\hline
\end{tabular}

*p value obtained from the exact Wilcoxon two-sample test.

GOS $=$ Glasgow Outcome Scale $; \mathrm{mRS}=$ modified Rankin Scale

GSC scores $\geq 9$ were $88 \%$ (95\% CI: 44-98) less likely than those with scores $<9$ to experience a new stroke. For female patients, the odds of new stroke did not change with GCS score. Both groups of patients improved on median GOS and mRS between discharge and follow-up, with no difference between the two groups (Table 4).

\section{Discussion}

\section{Incidence of Clinical Vasospasm}

The incidence of vasospasm after $\mathrm{SAH}$ is $70 \%,{ }^{12}$ with up to $40 \%$ of patients developing DIND. ${ }^{12-15}$ Hohlrieder et al reported the highest degree of vasospasm $(82.4 \%)$ in patients with $\mathrm{HH}$ score of $4 .{ }^{14} \mathrm{~A}$ pooled estimate of symptomatic vasospasm reported in six studies showed no difference between coiled or clipped groups $\left(32.3 \%\right.$ surgical vs $25.1 \%$ endovascular). ${ }^{15}$ Andaluz et al reported that in patients undergoing clipping of anterior communicating artery aneurysms, clinical vasospasm developed in $29.6 \%$ of patients who underwent FLT compared with $54.7 \%$ of patients who did not. ${ }^{4}$ However, Komotar, in 2009, reported no benefit of FLT in development of clinical vasospasm. $^{16}$

In the present study, $35 \%$ of the patients developed moderate or higher degrees of angiographic vasospasm with a $23.9 \%$ incidence of clinical vasospasm (DIND). This is slightly lower than the pooled estimate of $32.3 \%$ reported in a recent meta-analysis. ${ }^{15}$ This could partly be due to variability in how vasospasm is defined in literature. Compared with standard surgery, patients in group A had a 20\% lower incidence of DIND $(p=0.01)$, with a $14 \%$ reduction $(p=0.06)$ in ipsilateral radiographic vasospasm. We further analyzed all patients with FG 4 SAH (greatest blood burden). We found that, in this group, 19 of 81 patients $(23.8 \%)$ in group A and 13 of $30(43.3 \%)$ in group B developed DIND. This nearly $20 \%$ reduction in DIND was statistically significant $(\mathrm{p}=0.04)$.

Thus, our data suggest potential benefit of an aggressive surgical approach based on a reduction of DIND by $20 \%$ in patients surgically treated for ruptured anterior circulation aneurysms.

\section{Development of New Strokes}

The incidence of new infarcts after an $\mathrm{SAH}$ is reported between $20 \%$ and $60 \% .^{14,17-22}$ In the nimodipine trial, ${ }^{17}$ the incidence of new infarcts decreased from $53.3 \%$ to $42.4 \%$. Gruber et al reported a higher incidence in endovascular group of $37.7 \%$ and $21.6 \%$ in the surgical group while qualifying that this difference was from a skewed FG 4 infarction in endovascular group. ${ }^{19}$
A recent meta-analysis reported pooled estimates of $16.5 \%$ new strokes in surgical groups and $22.0 \%$ in endovascular groups. ${ }^{15}$

In our study, the overall incidence of new strokes was $29 \%$. The only group with significant differences in new stroke was the FG 4 group, where the percentage of patients with new stroke in group A was half that of group B (30\% and 64\%, respectively). It is, however, to be noted that because of the small number of patients in this subgroup, the results warrant further exploration.

Overall, this represents a $20 \%$ reduction in the incidence of clinically significant vasospasm and a $50 \%$ reduction in the development of new strokes in patients with high-grade aneurysm rupture (i.e. FG 4 with angiographic vasospasm), with the data reaching statistical significance.

\section{Limitations}

In addition to the retrospective nature of this single-institution study, a relatively small number of patients in our study preclude definitive conclusions. Differences in surgical experience of the two primary surgeons, in addition to surgical technique, could potentially have influenced our results. Moreover, surgeon B performed both open and endovascular procedures, lending the study to inherent selection bias.

Although group A included a number of intraoperative maneuvers including FLT and LM, use of papaverine in adventitial dissection of larger blood vessels, and aggressive clot removal, we cannot conclude which of these was responsible for the effects observed in our study. Additionally, patients in group A tended to be slightly older than those in group B; age is a confounding factor on development of angiographic vasospasm. However, the odds of DIND with increasing age were the same in subjects with FG 4. Despite reduction in clinically significant vasospasm (DIND and strokes) in the aggressive surgical group, the overall clinical outcome as assessed by GOS and mRS at discharge and last follow-up did not show a difference between the various groups. It has been suggested that the use of a gross outcome scale such as GOS may overlook subtle neuropsychological deficits that could be detected in patients with a "good" neurological outcome. ${ }^{23-25}$ The retrospective nature of the current study precluded detailed assessment of potential long-term differences in cognition, learning, and memory.

\section{Surgical Treatment in the Era of Endovascular Aneurysm Treatment}

Though there will undoubtedly be a role for surgical intervention for treatment of certain ruptured aneurysms, the safety and efficacy of endovascular techniques is continually improving. Overall outcomes have been shown to be improved by endovascular treatment compared with surgical treatment in two large randomized trials. ${ }^{26,27}$ It is therefore incumbent on surgeons to explore techniques that may improve outcomes in patients requiring surgery with regard to vasospasm and SDHCP. Having direct access to the region of concentrated subarachnoid blood and CSF cisterns seems to offer a theoretical opportunity to intervene to improve outcomes. Preliminary observations of additional "aggressive treatments" have shown some early promising results. Cisternal drainage has been shown to increase clot clearance rate. ${ }^{28}$ Techniques of cisternal lavage with head shaking has also shown promise in reducing stroke and vasospasm. ${ }^{28}$ Our data support the observation that surgical manipulation may have some 
beneficial effect. It will be incumbent on surgeons to examine in well-designed prospective trials which intraoperative maneuvers, available only to surgeons, either alone or in combination will reduce the delayed complications that too commonly occur following aneurysmal SAH.

\section{Conclusion}

We believe that aggressive clot removal and intraoperative papaverine-guided adventitial dissection during aneurysm surgery results in lower incidence of DIND and new strokes. This effect is most pronounced in patients with FG 4 SAH. Because of inherent limitations of this study, definite conclusions cannot be made and would involve further studies. Moreover, the relative contribution of individual components comprising "aggressive approach" on a lower incidence of DIND is unclear at this time.

\section{ACKNOWLEDGMENTS}

Statistical support for this study was supported by National Institutes of Health grant no. 1UL1RR031977-01 (to MOC).

\section{Disclosures}

The authors have nothing to disclose.

\section{REFERENCES}

1. Hosoda K, Fujita S, Kawaguchi T, Shose Y, Hamano S, Iwakura M. Effect of clot removal and surgical manipulation on regional cerebral blood flow and delayed vasospasm in early aneurysm surgery for subarachnoid hemorrhage. Surg Neurol. 1999;51:81-8.

2. Mura J, Rojas-Zalazar D, Ruíz A, Vintimilla LC, Marengo JJ. Improved outcome in high-grade aneurysmal subarachnoid hemorrhage by enhancement of endogenous clearance of cisternal blood clots: a prospective study that demonstrates the role of lamina terminalis fenestration combined with modern microsurgical cisternal blood evacuation. Minim Invasive Neurosurg. 2007;50:355-62.

3. Akyuz M, Tuncer R. The effects of fenestration of the interpeduncular cistern membrane arousted to the opening of lamina terminalis in patients with ruptured ACoA aneurysms: a prospective, comparative study. Acta Neurochir (Wien). 2006;148:725-32.

4. Andaluz N, Zuccarello M. Fenestration of the lamina terminalis as a valuable adjunct in aneurysm surgery. Neurosurgery. 2004;55:1050-9.

5. Kim JM, Jeon JY, Kim JH, et al. Influence of lamina terminalis fenestration on the occurrence of the shunt-dependent hydrocephalus in anterior communicating artery aneurysmal subarachnoid hemorrhage. J Korean Med Sci. 2006;21:113-8.

6. Komotar RJ, Olivi A, Rigamonti D, Tamargo RJ. Microsurgical fenestration of the lamina terminalis reduces the incidence of shunt-dependent hydrocephalus after aneurysmal subarachnoid hemorrhage. Neurosurgery. 2002;51:1403-13.

7. de Divitiis O, Angileri FF, d'Avella D, Tschabitscher M, Tomasello F. Microsurgical anatomic features of the lamina terminalis. Neurosurgery. 2002;50:563-70.

8. Dandy W. An operative procedure for hydrocephalus. Johns Hopkins Hosp Bull. 1922:189.

9. Auer LM, Mokry M. Disturbed cerebrospinal fluid circulation after subarachnoid hemorrhage and acute aneurysm surgery. Neurosurgery. 1990;26:804-9.

10. Dehdashti AR, Rilliet B, Rufenacht DA, de Tribolet N. Shuntdependent hydrocephalus after rupture of intracranial aneurysms: a prospective study of the influence of treatment modality. J Neurosurg. 2004;101:402-7.

11. Komotar RJ, Hahn DK, Kim GH, et al. Efficacy of lamina terminalis fenestration in reducing shunt-dependent hydrocephalus following aneurysmal subarachnoid hemorrhage: a systematic review. Clinical article. J Neurosurg. 2009;111:147-54.

12. Adams HP, Kassell NF, Torner JC, Haley EC. Predicting cerebral ischemia after aneurysmal subarachnoid hemorrhage: influences of clinical condition, CT results, and antifibrinolytic therapy. A report of the Cooperative Aneurysm Study. Neurology. 1987;37:1586-91.

13. Dehdashti AR, Mermillod B, Rufenacht DA, Reverdin A, de Tribolet $\mathrm{N}$. Does treatment modality of intracranial ruptured aneurysms influence the incidence of cerebral vasospasm and clinical outcome? Cerebrovasc Dis. 2004;17:53-60.

14. Hohlrieder M, Spiegel M, Hinterhoelzl J, et al. Cerebral vasospasm and ischaemic infarction in clipped and coiled intracranial aneurysm patients. Eur J Neurol. 2002;9:389-99.

15. de Oliveira JG, Beck J, Ulrich C, Rathert J, Raabe A, Seifert V. Comparison between clipping and coiling on the incidence of cerebral vasospasm after aneurysmal subarachnoid hemorrhage: a systematic review and meta-analysis. Neurosurg Rev. 2007;30: 22-31.

16. Komotar RJ, Hahn DK, Kim GH, et al. The impact of microsurgical fenestration of the lamina terminalis on shunt-dependent hydrocephalus and vasospasm after aneurysmal subarachnoid hemorrhage. Neurosurgery. 2008;62:123-34.

17. Petruk KC, West M, Mohr G, et al. Nimodipine treatment in poorgrade aneurysm patients. Results of a multicenter double-blind placebo-controlled trial. J Neurosurg. 1988;68:505-17.

18. Ohman J, Servo A, Heiskanen O. Risks factors for cerebral infarction in good-grade patients after aneurysmal subarachnoid hemorrhage and surgery: a prospective study. J Neurosurg. 1991;74: 14-20.

19. Gruber A, Ungersböck K, Reinprecht A, et al. Evaluation of cerebral vasospasm after early surgical and endovascular treatment of ruptured intracranial aneurysms. Neurosurgery. 1998;42:258-68.

20. Koivisto T, Vanninen R, Hurskainen H, Saari T, Hernesniemi J, Vapalahti M. Outcomes of early endovascular versus surgical treatment of ruptured cerebral aneurysms. A prospective randomized study. Stroke. 2000;31:2369-77.

21. Kassell NF, Torner JC, Haley EC, Jane JA, Adams HP, Kongable GL. The International Cooperative Study on the Timing of Aneurysm Surgery. Part 1: overall management results. J Neurosurg. 1990;73:18-36

22. Kassell NF, Torner JC, Jane JA, Haley EC, Adams HP. The International Cooperative Study on the Timing of Aneurysm Surgery. Part 2: surgical results. J Neurosurg. 1990;73:37-47.

23. Berry E, Jones RA, West CG, Brown JD. Outcome of subarachnoid haemorrhage. An analysis of surgical variables, cognitive and emotional sequelae related to SPECT scanning. Br J Neurosurg. 1997;11:378-87.

24. Ljunggren B, Sonesson B, Säveland H, Brandt L. Cognitive impairment and adjustment in patients without neurological deficits after aneurysmal SAH and early operation. J Neurosurg. 1985;62:673-9.

25. Ogden JA, Mee EW, Henning M. A prospective study of impairment of cognition and memory and recovery after subarachnoid hemorrhage. Neurosurgery. 1993;33:572-87.

26. McDougall CG, Spetzler RF, Zabramski JM, et al. The Barrow Ruptured Aneurysm Trial. J Neurosurg. 2012;116:135-44.

27. Molyneux A, Kerr R, Stratton I, et al. International Subarachnoid Aneurysm Trial (ISAT) of neurosurgical clipping versus endovascular coiling in 2143 patients with ruptured intracranial aneurysms: a randomised trial. Lancet. 2002;360:1267-74.

28. Shirao $\mathrm{S}$, Yoneda $\mathrm{H}$, Ishihara $\mathrm{H}$, et al. Fate of clots in patients with subarachnoid hemorrhage after different surgical treatment modality: a comparison between surgical clipping and Guglielmi detachable coil embolization. Neurosurgery. 2011;68: 966-73.

29. Nakagomi T, Furuya K, Nagashima H, et al. Surgical procedure and results of cisternal washing therapy for the prevention of cerebral vasospasm following SAH. Acta Neurochir Suppl. 2011;110: 105-9. 